\title{
Study On Critical Temperatures For Naphthalene And Chlorobenzene Removal During In Situ Steam Injection Remediation
}

Ru xue Liu

Jilin University

Xinru Yang

Jilin University

Yongsheng Zhao ( $\nabla$ zhaoyongsheng@jlu.edu.cn )

Department of Environmental engineering https://orcid.org/0000-0002-5804-0473

\section{Research Article}

Keywords: Steam injection, Naphthalene, Chlorobenzene, Critical temperatures

Posted Date: April 19th, 2021

DOl: https://doi.org/10.21203/rs.3.rs-347228/v1

License: () (1) This work is licensed under a Creative Commons Attribution 4.0 International License. Read Full License 


\section{Abstract}

Steam injection is an effective technique for the in situ remediation of volatile and semi-volatile organic contaminants. In this study, the influence of temperature and media on the removal of organic pollutants, such as naphthalene and chlorobenzene, was investigated in the remediation process through batch and remediation experiments, and the solid, liquid, and gaseous phase migration and transformation of organic pollutants during remediation were evaluated. The results demonstrated that the temperature significantly influenced the removal of organic pollutants. It was found that the critical temperatures for naphthalene and chlorobenzene were $50^{\circ} \mathrm{C}$ and $30^{\circ} \mathrm{C}$, respectively. When the temperature was higher than the critical temperature, the final removal rates of naphthalene and chlorobenzene reached over $94 \%$ and $96 \%$, respectively. The remediation area of chlorobenzene determined according to the critical temperature has a good result; the error compared with the actual remediation area in both coarse sand and fine sand was approximately $8.7 \%$. In the simulation tank, the temperature changes can be divided into three stages: the ambient temperature stage, the temperature rapid rise stage, and the stable stage. Moreover, we found that the remediation effect of aquifers is not only related to temperature, but also to the location of the SVE well (soil vapour extraction). These findings reveal the main factors affecting the application of hot steam technology and the relationship between the temperature field and contamination field in the remediation process.

\section{Introduction}

Steam injection was originally developed for the petroleum industry to increase oil recovery from ground repositories (Abd Rahman et al., 2016; Davis, 1997; Hadim, Shah, \& Korfiatis, 1993). This technique is now used for in situ remediation of sites contaminated with dense non-aqueous phase liquid (DNAPL) and is one of the most promising technologies for DNAPL remediation (Allawzi \& Al-Jarrah, 2008; REINHARD SCHMIDT, 1998; Udell, 1998; Zuhair Al Yousef1, 2014). However, owing to the uncertainty of many influencing factors, the repair effect cannot reach the expectation when the technique is applied to the contaminated site. Hence, it is necessary to investigate the factors influencing the application of steam injection.

Several studies have described the factors influencing steam injection, including DNAPL properties, such as volatility (Udell \& Stewart, 1992). The volatility of DNAPLs is an important factor affecting the application of steam injection; hence, chlorobenzene (with high volatility) and naphthalene (with relatively low volatility) were selected as the target pollutants in this study (Shen et al., 2007; Yuan et al., 2020). Other factors influencing the remediation of contaminated sites by steam injection include properties related to the porosity of the media (Nilsson et al., 2011); the DNAPL removal rate is higher in media with high permeability than in those with low permeability (Tsakiroglou, 2011; Tzovolou, Aggelopoulos, Theodoropoulou, \& Tsakiroglou, 2010), which have a great influence on the repair effect of steam. Therefore, it is necessary to clarify the effects of the medium on steam repair and their mechanisms. It remains unclear whether the influence of the medium arises due to the mass transfer of steam. To address this, the removal rates of different media at the same temperatures were studied. The heterogeneity of a medium affects the removal rate and remediation period for DNAPLs (H. Class 2002; Tzovolou et al., 2010). The most important factor affecting the efficiency of steam-enhanced extraction is the location of the steam injection wells (Abd Rahman et al., 2016). It is important to determine the range of influence of steam-enhanced extraction. However, limited research has 
been conducted on this topic, and no definite method to determine this has been suggested. Therefore, quantifying the influencing factors is of great significance for remediation purposes.

The solubility of organic pollutants changes with temperature, and previous research has reported that the solubility of some organic pollutants such as Trichloroethylene (TCE) and dichloroethylene (DCE) first decreased and then increased with the increase in temperature, and the solubility was the lowest at $40^{\circ} \mathrm{C}$. The solubility of polychlorinated biphenyls(PCBs)and polycyclic aromatic hydrocarbons (PACs) increases gradually as temperature increases (Koproch, Dahmke, \& Kober, 2019). The volatilization of organic pollutants in the aqueous phase is also affected by temperature. However, the effect of temperature on dissolved organic matter remains unclear. When steam is injected, the temperature is highest around the injection well and decreases gradually as the distance from the injection well increases, forming a temperature gradient (Gudbjerg, Sonnenborg, \& Jensen, 2004; Gudbjerg, Trötschler, Färber, Sonnenborg, \& Jensen, 2004; H. Class 2002; Jacob Gudbjerg, 2005; Ochs, Class, Färber, \& Helmig, 2010). A similar finding was observed in this study; however, it is unclear which temperature is optimal for complete pollutant removal. Identifying this temperature will elucidate the optimal areas of steam injection. Therefore, to determine the spacing of steam injection wells, it is necessary to study the critical temperature of pollutants. When hot steam is used to repair a contaminated site, the medium greatly affects the repair effect. Therefore, it is necessary to study the influence of the medium on steam migration.

Therefore, determining and quantifying the influencing factors is necessary. This study aimed to (1) quantitatively characterise the influencing factors; (2) clarify the effect of temperature on the three phase conversion of gaseous/liquid/solid phases of organic contaminants; (3) determine the temperature-field distribution and coupling relationship between the temperature field and pollution field for steam injection; and (4) predict and calculate the area of influence for steam injection.

\section{Materials And Methods}

\subsection{Materials}

AR-grade naphthalene was obtained from Sinopharm Chemical Reagent Co. Ltd., AR-grade chlorobenzene and n-hexane ( $\geq 97 \%$ ) were purchased from Guangfu Chemical Co. Ltd., and AR-grade methyl alcohol and ethyl alcohol were purchased from Beijing Chemical Plant Co. Ltd. All materials were used as received without further purification, and all aqueous solutions were prepared with deionised water.

\subsection{Experimental methods}

\subsubsection{Influence of temperature and media}

Batch experiments were conducted to determine the effect of temperature and various media on DNAPL removal. Crystalline naphthalene and non-aqueous phase chlorobenzene were homogeneously dissolved prior to use in methanol. For these tests, $500 \mathrm{~g}$ of sand (coarse, medium, and fine and silt) were added to $500 \mathrm{~mL}$ headspace bottles before the mixed solution $(200 \mathrm{~mL})$ was added, with initial chlorobenzene and naphthalene concentrations of 100 and $20 \mathrm{mg} \cdot \mathrm{L}^{-1}$. The headspace bottle was connected to a bottle of activated carbon. The physical properties of the river sand samples used in the tests are listed in Table 1. A series of 
experiments were carried out at ambient temperatures of $10,30,50,70$, and $90^{\circ} \mathrm{C}$. Each set of experiments ensured that the temperature of the entire system was maintained at the set temperature and shaken at a constant speed on a constant temperature shaker. Aqueous samples collected using disposable syringes at selected time intervals (0-270 min) were analysed for naphthalene and chlorobenzene concentrations. At the end of the experiment, the final soil samples and activated carbon samples were collected, and the concentrations of naphthalene and chlorobenzene in soil and air were analysed.

Table 1

Properties of river sand samples in tests

\begin{tabular}{|lll|}
\hline Soil type & Particle size $(\mathrm{mm})$ & Permeability coefficient $(\mathrm{cm} / \mathrm{s})$ \\
\hline Coarse sand & $0.5-1$ & $7.9 \times 10^{-2}$ \\
\hline Medium sand & $0.25-0.5$ & $4.2 \times 10^{-2}$ \\
\hline Fine sand & $0.1-0.25$ & $3.54 \times 10^{-3}$ \\
\hline Silt & $0.05-0.1$ & $7.4 \times 10^{-4}$ \\
\hline
\end{tabular}

\subsubsection{D tank experiments}

2D tank experiments were conducted in a glass sandbox (60 cm [length], $50 \mathrm{~cm}$ [height], and $4 \mathrm{~cm}$ [width]) (Fig. 1). We conducted two sets of experiments; each group of experiments with coarse sand and fine sand was used as the main packing medium. The injection well installed at the bottom centre of the tank for stem injection was composed of a cylinder and many tiny pores at the top (diameter, $4 \mathrm{~cm}$; height, $7.5 \mathrm{~cm}$ ). The tiny pores were covered with gauze to prevent sand from entering the injection well. An air outlet was arranged on the upper right of the tank, and the air outlet was connected to a bottle containing activated carbon.

Before the experiment, tap water was continuously injected at a rate of $0.1 \mathrm{~m} \cdot \mathrm{d}^{-1}$ by a peristaltic pump to ensure uniformity of the porous media and prevent the presence of entrapped air. Subsequently, chlorobenzene with a concentration of $200 \mathrm{mg} / \mathrm{L}$ was injected into the lower left water inlet until the concentration detected at the upper right water outlet was the same as the water inlet, which simulated the formation and stabilisation of the chlorobenzene contamination plume. There were 24 sampling ports, represented as holes 1-24 in Fig. 1, at the front of the tank to monitor the temperature using a multi-channel temperature patrol instrument (Shen Zhen Hua Xin Measuring Instrument Company). Aqueous samples were collected using disposable syringes at selected time intervals ( $0-270 \mathrm{~min})$. Connections between parts of the apparatus were carefully sealed and tests for air-tightness were performed before the experiment to ensure minimal leakage. Steam was generated at a constant rate by a $3 \mathrm{~kW}$ steam generator (Norbest Machinery Manufacturing Co. Ltd., Wuhan, China), supplied by a constant flux of water to generate steam at a rate of 1 $\mathrm{kg} \cdot \mathrm{h}^{-1}$. The steam generator produced saturated steam at a temperature of $120^{\circ} \mathrm{C}$ and a saturated steam pressure of $200 \mathrm{kPa}$. The temperatures were continuously measured in the sandbox.

\subsubsection{Analytical methods}

The naphthalene concentration was analysed using a UV-visible spectrophotometer (Thermo Scientific, Evolution 220) at a wavelength of $220 \mathrm{~nm}$. Chlorobenzene samples were automatically injected with a purge 
and trap concentrator (Teledyne Tekmar, USA), and the concentration of chlorobenzene in the aqueous phase was measured using a gas chromatograph-mass spectrometer (GC-MS, 7890A-7000B, Agilent Technologies, USA). The separation was performed on an Agilent HP-5MS capillary column (length: 30 m, inner diameter: $0.250 \mathrm{~mm}$, film thickness: $0.25 \mathrm{~mm}$ ) with a split ratio of 50:1. The temperature setting for chlorobenzene was changed as follows: initially held at $100^{\circ} \mathrm{C}$ for $1 \mathrm{~min}$, then increased to $200^{\circ} \mathrm{C}$ at $20^{\circ} \mathrm{C} / \mathrm{min}$, and held for $5 \mathrm{~min}$. The temperature program of naphthalene was as follows: initially held at $80^{\circ} \mathrm{C}$ for $2 \mathrm{~min}$, then increased to $220^{\circ} \mathrm{C}$ at $20^{\circ} \mathrm{C} / \mathrm{min}$, and held for $10 \mathrm{~min}$, and the split ratio was $25: 1$. The concentrations of $\mathrm{CB}$ and naphthalene in the solid phase were also measured using the same gas chromatograph-mass spectrometer.

\section{Results And Discussion}

\subsection{Influencing Factors}

\subsubsection{Effect of temperature}

Figure 2 shows the changes in chlorobenzene concentrations at different temperatures in different media. With an increase in temperature, the concentration of naphthalene decreased gradually, while the removal efficiency increased. However, at temperatures $\geq 30^{\circ} \mathrm{C}$, chlorobenzene removal was greater. At chlorobenzene $30^{\circ} \mathrm{C}$, the removal rate of the four media was $>96 \%$; therefore, this temperature could be used as an index temperature for removing chlorobenzene. We define $30{ }^{\circ} \mathrm{C}$ as the critical temperature of chlorobenzene, that is, when the temperature is higher than the critical temperature, chlorobenzene has a good removal effect. Determining the critical temperature can allow for an improved design that reduces energy consumption, thereby making this approach more economical. This may be because the increase in temperature enhances the volatilization of pollutants, and pollutants can form azeotropes with other substances such as water, which reduces the boiling point (Maalem, Zarfa, Tamene, Fedali, \& Madani, 2020). This discovery could be combined with numerical simulations or an experimental study of the temperature-field distribution to determine the injection well spacing and remediation-area. These results indicate that temperature has a great influence on the removal of volatile pollutants; hence, it is necessary to define the threshold temperature of various pollutants.

Figure 3 describes the changes in naphthalene concentrations at different temperatures in different media. The removal rate of naphthalene was similar to that of chlorobenzene. However, the boiling point of naphthalene is higher than that of chlorobenzene, and the removal of naphthalene can be improved when the temperature exceeds $50{ }^{\circ} \mathrm{C}$, that is, the removal rate is higher than $94.5 \%$. Therefore, the critical temperature for removal naphthalene was $50^{\circ} \mathrm{C}$. There can be a rebound in contaminant concentrations during their removal. This mainly occurs because with the removal of naphthalene in water, it gradually desorbs from the medium and enters the aqueous phase, resulting in an increase in its concentration in the aqueous phase. Therefore, the pollutants were verified to be removed in the order of liquid-gas, solid-liquid, and liquid-gas. This phenomenon was more noticeable at low-temperatures and in media with low-permeability. Thermal desorption can occur with a rise in temperature, which not only slows the rebound phenomenon generated through pollutant removal, but also removes naphthalene in the solid phase more effectively; however, thermal decomposition of naphthalene was not observed in this experiment. 


\subsubsection{Influence of medium}

Figure 4 shows the changes in naphthalene concentrations in various media at $10,30,50,70, a^{\circ} 90^{\circ} \mathrm{C}$. The results suggest that the medium had little effect on the removal of naphthalene at different temperatures, and the removal rate of naphthalene in various media exceeded $94 \%$ at temperatures $\geq 50^{\circ} \mathrm{C}$. That is, the main reason that the medium affects the removal effect is the propagation of steam in the medium. A medium with lower permeability resulted in a lower concentration of naphthalene in the aqueous phase during the reaction. This is because naphthalene is easily adsorbed onto media with low permeability, which lowers the naphthalene content in water. This phenomenon was more obvious below $50^{\circ} \mathrm{C}$. A rebound in naphthalene concentrations was obvious at ambient temperatures of 10 and $30^{\circ} \mathrm{C}$. An increase in temperature reduced the difference in removal-efficiency between the four media but had little effect on the final removal rate.

Changes in chlorobenzene concentration in different media at $10,30,50,70$, and $90^{\circ} \mathrm{C}$ are shown in Fig. 5 . The results suggested that the media had little effect on CB removal and only affected the chlorobenzene removal efficiency. However, the chlorobenzene removal rate of different media was over $97 \%$ after 150 min at temperatures $\geq 30^{\circ} \mathrm{C}$. These results indicate that heat transport is the main factor that affects the site remediation effect.

\subsection{Migration and transformation of pollutants}

Figure 6 depicts the percentage of naphthalene $(a-d)$ and chlorobenzene $(e-h)$ in a solid/liquid/gaseous phase at different temperatures in coarse, medium, and fine sand and silt. At the end of the reaction, naphthalene mostly existed in a gaseous form, while a small amount remained in liquid and solid phases. The mass of naphthalene in the gaseous phase increased with increasing temperature. According to the conservation of mass in multiphase system, the mass of naphthalene in the liquid and solid phases gradually decreased. At temperatures $>50^{\circ} \mathrm{C},>93 \%$ of naphthalene converted into gas in all media. Therefore, naphthalene could be more effectively removed at temperatures $>50{ }^{\circ} \mathrm{C}$. Being highly volatile, chlorobenzene easily converted to gaseous chlorobenzene; only at low temperatures would small portions of chlorobenzene exist in the liquid phase, whereas the solid chlorobenzene content is considerably low and can be ignored. Moreover, the results suggest that a medium has little influence on the amount of naphthalene converted into a gaseous state, i.e., it has little influence on the final removal rate of naphthalene (Fig. S1). The permeability of a medium affected the naphthalene content in the liquid/solid phase, which was clear from the observations of silt. The content of naphthalene in silt at $90{ }^{\circ} \mathrm{C}$ is 2.8 times of that in coarse sand, while the content of naphthalene in silt at $10^{\circ} \mathrm{C}$ is 10 times of that in coarse sand. Therefore, temperature has an effect on the content of naphthalene in the soil. At temperatures higher than $30^{\circ} \mathrm{C}$, almost all of it converted to gaseous chlorobenzene, and chlorobenzene in the liquid and solid phases was almost completely removed (Fig. S2). These results show that the content of pollutants in sand is not only related to medium but also to temperature and pollutant volatility. However, the pollutants in the gas phase are only related to the temperature and volatility of the pollutants but not to the particle size of the medium.

\subsection{Henry's constant}

The dimensionless $\mathrm{H}$ described as the volatility constant is defined as the relationship between concentration of the compound in the gaseous $\left(\mathrm{C}_{\mathrm{g}}\right)$ and the aqueous phase $\left(\mathrm{C}_{\mathrm{w}}\right)$ (Chen, Freedman, Falta, \& Murdoch, 2012; 


$$
\mathrm{H}=\frac{\mathrm{Cg}}{\mathrm{Cw}}
$$

The other commonly used expression of $\mathrm{H}$ has units of $\left[\mathrm{atm} \cdot \mathrm{m}^{3} \mathrm{~mol}^{-1}\right.$ ] and is usually expressed as $\mathrm{k}_{\mathrm{H}}$ via the vapour pressure $\left(P_{\mathrm{v}}\right)$ (Chen et al., 2012; GORM HERON, 1998; Heron, Christensen, \& Enfield, 1998; Schwardt et al., 2021), as follows:

$$
\mathrm{k}_{\mathrm{H}}=\frac{\mathrm{Pv}}{\mathrm{Cw}}
$$

$\mathrm{H}$ and $\mathrm{k}_{\mathrm{H}}$ are related to the temperature (T) and ideal gas constant (R) (Chen et al., 2012; GORM HERON, 1998; Heron et al., 1998; Schwardt et al., 2021):

$\mathrm{k}_{\mathrm{H}}=\mathrm{HR} \mathrm{R}(3)$

In this study, because of the presence of medium, we define the relationship between the concentration of organic matter in the water phase $\left(\mathrm{Cw}^{\prime}\right)$ and the gas phase $\left(\mathrm{Cg}^{\prime}\right)$ as $\mathrm{H}^{\prime}$ :

$$
\mathrm{H}^{\prime}=\frac{C g^{\prime}}{C w^{\prime}}
$$

According to Formula (4), $\mathrm{H}$ was calculated under different experimental conditions, as shown in Table 1. According to the calculation, the results show that the Henry constant increases with the increase in temperature in the same medium, which conforms to the general law of Henry constant changing with temperature. For example, in coarse sand, $\mathrm{H}^{\prime}$ at $90^{\circ} \mathrm{C}$ is 32.4 higher than that at $10^{\circ} \mathrm{C}$ (chlorobenzene). Different media also affect Henry's constant $\mathrm{H}^{\prime}$. Because the medium has a certain adsorption and other characteristics, $\mathrm{H}^{\prime}$ will increase with a decrease in the medium particle size. Under the same experimental conditions, the Henry constant $\mathrm{H}^{\prime}$ of chlorobenzene was more than ten times that of naphthalene. This is because $\mathrm{CB}$ has a lower boiling point and stronger volatility than naphthalene. These results show that $\mathrm{H}^{\prime}$ has a strong correlation with temperature; therefore, it is very important to determine the temperature distribution of hot steam.

3.4 Temperature field distribution and remediation effect of chlorobenzene in a 2D sandbox

\subsubsection{Temperature-field distribution in a 2D sandbox}

The distribution of the temperature field at different times is shown in Fig. 7. In the figure, the blue square represents the steam injection point, and the blue solid line represents the centre line of the tank. The temperature above the steam injection well was the highest, and it decreased gradually with increasing distance from the steam injection well. The high-temperature zone gradually migrates upward with the injection of steam. This is mainly because condensation occurs during the upward migration of steam, and the condensed water migrates downward, resulting in a decrease in temperature or heating rate, which causes the high-temperature zone to migrate upwards. In the case of different times and different media, the temperature is basically symmetrical on both sides of the steam injection well. The heat transfer in coarse 
sand was faster than that in fine sand, but the final heating area showed little difference (Fig. 8). In this experiment, the heat transfer in the sandbox mainly depended on the heat conduction and heat convection. Heat transfer is mainly affected by the thermal conductivity of sand, specific heat capacity, porosity, and other factors, while the thermal conductivity of coarse sand is greater than that of fine sand, and the porosity is less than that of fine sand, making heat transfer in coarse sand faster. Owing to the existence of the heat pipe effect in fine sand, the final affected area of heat in fine sand is not different from that of coarse sand (Udell, 1983 ; UDELL, 1985).

Figure 9 depicts the temperature changes at different positions in the third row above the steam injection point in the coarse sand (holes 13-18 in Fig. 1), with the injection point as the centre, the distance from the centre to the left is negative, and the right is positive. At the same distance from the injection well, there is little difference in the temperature variation, which basically presents a symmetrical distribution. Figure 10 shows the temperature changes at the same position in coarse and fine sand. The first row (holes 1-6 in Fig. 1) and the fourth row (holes 19-24 in Fig. 1) above the steam injection point are selected. The first row (holes 1-6) close to the steam injection point had a higher temperature for fine sand than coarse sand. In the fourth row, the temperature of fine sand in holes 21 and 22 is higher than that of coarse sand, whereas in the other four points, the temperature of coarse sand is higher than that of fine sand. Moreover, the heating rate of coarse sand in the same location was higher than that of fine sand. Hot steam migrates more easily in coarse sand than in fine sand, and hot steam migrates upward more easily, so the hot steam in coarse sand migrates faster, resulting in a higher temperature in the upper part of the tank. However, in fine sand, the vertical migration of hot steam is inhibited, which causes it to migrate in the transverse direction, leading to an increase in temperature in the transverse direction at the lower part of the tank. There are similar heating laws in different locations and different media; that is, the temperature changes in the media with time can be divided into three stages: (1) the ambient temperature stage, (2) the rapid temperature rise stage, and (3) the stable temperature stage. The closer to the steam injection well, the shorter the ambient temperature stage and the shorter the time required to reach the stable temperature stage.

\subsubsection{Remediation effect of chlorobenzene in a 2D sandbox}

The chlorobenzene concentrations at different times are shown in Fig. 11. During the experiment, the outlet was arranged at the top right of the tank, resulting in the removal process of $C B$ on the left and right sides of the injection well did not show a symmetrical distribution. The removal effect of chlorobenzene was significantly better on the right side of the injection well than on the left side, indicating that the location of the SVE is very important.

The remediation area was calculated according to the critical temperature of the $\mathrm{CB}$ in the batch experiment (Table 2). Comparing the remediation area with the actual remediation area of $C B$, it was found that there is not much difference between the two, and the actual remediation area is larger than the remediation area according to the critical temperature. Therefore, the critical temperature of pollutants can be used to determine the remediation area and radius to a certain extent. 
Table 2

Calculation of Henry's law constants under different experimental conditions

\begin{tabular}{|c|c|c|c|c|c|c|c|}
\hline Contaminant & $\begin{array}{l}\text { Temperature } \\
\left({ }^{\circ} \mathrm{C}\right)\end{array}$ & Medium & H & Contaminant & $\begin{array}{l}\text { Temperature } \\
\left({ }^{\circ} \mathrm{C}\right)\end{array}$ & Medium & $\mathrm{H}$ \\
\hline \multirow[t]{5}{*}{ Naphthalene } & 10 & \multirow{5}{*}{$\begin{array}{l}\text { Coarse } \\
\text { sand }\end{array}$} & 7.18 & \multirow[t]{5}{*}{ Chlorobenzene } & 10 & \multirow{5}{*}{$\begin{array}{l}\text { Coarse } \\
\text { sand }\end{array}$} & 60.01 \\
\hline & 30 & & 7.96 & & 30 & & 439.8 \\
\hline & 50 & & & & 50 & & 568.6 \\
\hline & 70 & & 54.72 & & 70 & & 861.9 \\
\hline & 90 & & 92.4 & & 90 & & 1584 \\
\hline \multirow[t]{5}{*}{ Naphthalene } & 10 & \multirow{5}{*}{$\begin{array}{l}\text { Medium } \\
\text { sand }\end{array}$} & 6.12 & \multirow[t]{5}{*}{ Chlorobenzene } & 10 & \multirow{5}{*}{$\begin{array}{l}\text { Medium } \\
\text { sand }\end{array}$} & 25.88 \\
\hline & 30 & & 7.15 & & 30 & & 89.4 \\
\hline & 50 & & 16.3 & & 50 & & 125.9 \\
\hline & 70 & & 45.1 & & 70 & & 531.6 \\
\hline & 90 & & 72.7 & & 90 & & 557.6. \\
\hline \multirow[t]{5}{*}{ Naphthalene } & 10 & \multirow{5}{*}{$\begin{array}{l}\text { Fine } \\
\text { sand }\end{array}$} & 6.19 & \multirow[t]{5}{*}{ Chlorobenzene } & 10 & \multirow{5}{*}{$\begin{array}{l}\text { Fine } \\
\text { sand }\end{array}$} & 29.8 \\
\hline & 30 & & 7.48 & & 30 & & 67.1 \\
\hline & 50 & & 16.8 & & 50 & & 97.5 \\
\hline & 70 & & 63.4 & & 70 & & 294.2 \\
\hline & 90 & & 120.8 & & 90 & & 860.9 \\
\hline \multirow[t]{5}{*}{ Naphthalene } & 10 & \multirow[t]{5}{*}{ Silt } & 9.76 & \multirow[t]{5}{*}{ Chlorobenzene } & 10 & \multirow[t]{5}{*}{ Silt } & 51.4 \\
\hline & 30 & & 13 & & 30 & & 73.1 \\
\hline & 50 & & 30.8 & & 50 & & 454.8 \\
\hline & 70 & & 37.6 & & 70 & & 786.3 \\
\hline & 90 & & 72.3 & & 90 & & 1163.3 \\
\hline
\end{tabular}

Table 3

Total heating zone area, heating zone area above $30{ }^{\circ} \mathrm{C}$, and removal area of chlorobenzene

\begin{tabular}{|c|c|c|c|}
\hline Medium & $\begin{array}{l}\text { Heating zone (above ambient } \\
\text { temperature) }\left(\mathrm{cm}^{2}\right)\end{array}$ & $\begin{array}{l}\text { Heating zone (above } \\
\left.30^{\circ} \mathrm{C}\right) \\
\left(\mathrm{cm}^{2}\right)\end{array}$ & $\begin{array}{l}\text { Chlorobenzene removal } \\
\text { area }\left(\mathrm{cm}^{2}\right)\end{array}$ \\
\hline $\begin{array}{l}\text { Coarse } \\
\text { sand }\end{array}$ & 3000 & 2543.73 & 2787.93 \\
\hline $\begin{array}{l}\text { Find } \\
\text { sand }\end{array}$ & 2905.26 & 2442.65 & 2675.88 \\
\hline
\end{tabular}


Chlorobenzene exists in three forms, in the gas phase or adsorbed on the solid and liquid phases. The final mass balance of each component was determined, and the percentage of each component is shown in Fig. 12. The results indicate that $95 \%$ of the $C B$ in the coarse sand is converted into the gas phase, and $96 \%$ of the $C B$ in the fine sand is finally converted into the gas phase. Chlorobenzene $(600 \mathrm{mg})$ completely entered the tank, and the quality of chlorobenzene in the aqueous phase was $21 \mathrm{mg}$ and $15 \mathrm{mg}$ in coarse sand and fine sand at $270 \mathrm{~min}$, respectively. However, because the increase in temperature promotes the desorption of $\mathrm{CB}$ from the medium, the final solid phase adsorption of chlorobenzene only accounted for $0.5 \%$ and $1 \%$ in the coarse sand and fine sand, respectively. This illustrates that hot steam can achieve a good removal effect in both coarse sand and fine sand. Moreover, incomplete removal caused by the trailing phenomenon produced by AS technology was not observed, and it can enhance the removal of pollutants from the solid phase.

\section{Conclusion}

In this study, it was found that the critical temperatures of naphthalene and chlorobenzene were $50^{\circ} \mathrm{C}$ and $30^{\circ} \mathrm{C}$, respectively. When the temperature exceeded the critical temperature, both naphthalene and chlorobenzene exhibited better removal effects, and the medium had a minimal impact on removal. Therefore, the main factor influencing the effect of the medium on pollutant removal at the site was heat transfer. The results of this study indicate a strong effect of temperature on Henry's law constants $\mathrm{H}^{\prime}$, with increases between 10-fold (naphthalene) and 30-fold (chlorobenzene) as the temperature increased from 10 to $90^{\circ} \mathrm{C}$. In the two-dimensional simulation tank, it was found that the temperature variation in the medium can be divided into three stages: ambient temperature, rapid heating, and stable stages. Moreover, it was found that temperature and the location of the SVE well were the most influential on the remediation effect of the aquifer. Additionally, the reliability of the critical temperature was demonstrated by two-dimensional simulation tank experiments. The error between the remediation area according to the critical temperature and the actual remediation area of chlorobenzene was $8.7 \%$ in coarse sand and fine sand, which proved that the critical temperature could determine the remediation area.

\section{Declarations}

\section{Ethics approval and consent to participate}

Not applicable.

\section{Consent for publication}

Not applicable.

\section{Availability of data and materials}

The data used and analyzed during the current study are available from the corresponding author on reasonable request.

\section{Competing interests}


The authors declare that they have no known competing financial interests or personal relationships that could have appeared to influence the work reported in this paper.

\section{Funding}

This work was supported by the National Nature Science Foundation of China (Grant No. 41530636), National and Local Joint Engineering Laboratory for Petrochemical Contaminated Site Control and Remediation Technology of Jilin University, Jilin Provincial Key Laboratory of Water Resources and Environment of Jilin University, and Key Laboratory of Groundwater Resources and Environment of Ministry of Education (Jilin University).

\section{Authors' contributions}

Ruxue Liu: Conceptualization, Investigation, Formal analysis, Writing-original draft. Xinru Yang: Investigation, Validation. Yongsheng Zhao: Conceptualization, Resources, Writing-review \& editing.

\section{Acknowledgments}

This study was financially supported by the Key Project of National Natural Science Foundation of China (Grant No. 41530636). The authors are grateful for the support of the Key Laboratory of Groundwater Resources and Environment, Ministryof Education.

\section{References}

Abd Rahman, N., Azizan, N. A., Kamaruddin, S. A., Chelliapan, S., Mohd Jaini, Z., Yunus, R., \& Rahmat, S. N. (2016). Steam-Enhanced Extraction Experiments, Simulations and Field Studies for Dense Non-Aqueous Phase Liquid Removal: A Review. MATEC Web of Conferences, 47. doi:10.1051/matecconf/20164705012

Allawzi, M. A., \& Al-Jarrah, N. (2008). <Study of the Effect of Steam Injection on Crude Oil Displacement Yield from an Oil Contaminated Soil Bed.pdf>. ordan Journal of Civil Engineering, 2.

Chen, F., Freedman, D. L., Falta, R. W., \& Murdoch, L. C. (2012). Henry's law constants of chlorinated solvents at elevated temperatures. Chemosphere, 86(2), 156-165. doi:10.1016/j.chemosphere.2011.10.004

Davis, E. L. (1997). <How Heat Can Enhance In-situ Soil and Aquifer Remediation How Heat Can Enhance Insitu Soil and Aquifer Remediation.pdf>. United States Environmental Protection Agency,Ground Water Issue, EPA/540/S-597/502

GORM HERON, T. H. C., CARL G. ENFIELD (1998). <Henry's law constant for trichloroethylene between 10 and $95^{\circ} \mathrm{C}$. pdf>. Environ. Sci. Technol. , 32, 433-1437.

Gudbjerg, J., Sonnenborg, T. O., \& Jensen, K. H. (2004). Remediation of NAPL below the water table by steaminduced heat conduction. J Contam Hydrol, 72(1-4), 207-225. doi:10.1016/j.jconhyd.2003.11.001

Gudbjerg, J., Trötschler, O., Färber, A., Sonnenborg, T. O., \& Jensen, K. H. (2004). On spurious water flow during numerical simulation of steam injection into water-saturated soil. Journal of Contaminant Hydrology, 75(3-4), 
H. Class, R. H. (2002). Numerical simulation of non-isothermal multiphase multicomponent processes in porous media.

2. Applications for the injection of steam and air. Advances in Water Resources, 551-564.

Hadim, A., Shah, F. H., \& Korfiatis, G. P. (1993). Laboratory studies of steam stripping of LNAPL-contaminated soils. Journal of Soil Contamination, 2(1), 37-58. doi:10.1080/15320389309383428

Heron, G., Christensen, T. H., \& Enfield, C. G. (1998). Henry's law constant for trichloroethylene between 10 and $95^{\circ} \mathrm{C}$. Environmental Science and Technology, 32(10), 1433-1437. doi:10.1021/es 9707015

Jacob Gudbjerg, T. H., Torben O. Sonnenborg, and Karsten H. Jensen. (2005). <Three-Dimensional Numerical Modeling of Steam Override Observed at a Full-Scale Remediation of an Unconfined Aquifer.pdf>. Ground Water Monitoring \& Remediation 116-127.

Koproch, N., Dahmke, A., \& Kober, R. (2019). The aqueous solubility of common organic groundwater contaminants as a function of temperature between 5 and 70 degrees C. Chemosphere, 217, 166-175. doi:10.1016/j.chemosphere.2018.10.153

Maalem, Y., Zarfa, A., Tamene, Y., Fedali, S., \& Madani, H. (2020). Prediction of thermodynamic properties of the ternary azeotropic mixtures. Fluid Phase Equilibria, 517. doi:10.1016/j.fluid.2020.112613

Nilsson, B., Tzovolou, D., Jeczalik, M., Kasela, T., Slack, W., Klint, K. E., .. . Tsakiroglou, C. D. (2011). Combining steam injection with hydraulic fracturing for the in situ remediation of the unsaturated zone of a fractured soil polluted by jet fuel. J Environ Manage, 92(3), 695-707. doi:10.1016/j.jenvman.2010.10.004

Ochs, S. O., Class, H., Färber, A., \& Helmig, R. (2010). Methods for predicting the spreading of steam below the water table during subsurface remediation. Water Resources Research, 46(5). doi:10.1029/2007wr006401

REINHARD SCHMIDT, C. B. A. F. (1998). <LNAPL and DNAPL behaviour during steam injection into the unsaturated zone.pdf>. Groundwater Quality: Remediation and Protection.

Schwardt, A., Dahmke, A., \& Köber, R. (2021). Henry's law constants of volatile organic compounds between 0 and $95^{\circ} \mathrm{C}$ - Data compilation and complementation in context of urban temperature increases of the subsurface. Chemosphere, 272. doi:10.1016/j.chemosphere.2021.129858

Shen, X., Sun, Y., Ma, Z., Zhang, P., Zhang, C., \& Zhu, L. (2007). Effects of mixed surfactants on the volatilization of naphthalene from aqueous solutions. Journal of Hazardous Materials, 140(1), 187-193. doi:https://doi.org/10.1016/j.jhazmat.2006.06.137

Tsakiroglou, D. N. T. C. A. A. M. A. T. C. D. (2011). <Soil heating for enhanced remediation of chlorinated solvents_a laboratory study on resistive heating and vapor extraction in a silty, low-permeable soil contaminated with trichloroethylene.pdf>. J Soils Sediments 72-81. 
Tzovolou, D. N., Aggelopoulos, C. A., Theodoropoulou, M. A., \& Tsakiroglou, C. D. (2010). Remediation of the unsaturated zone of NAPL-polluted low permeability soils with steam injection: an experimental study. Journal of Soils and Sediments, 11(1), 72-81. doi:10.1007/s11368-010-0268-5

Udell, K. S. (1983 ). < Heat Transfer in Porous Media Heated From Above With Evaporation Condensation and Capillary Effect.pdf>. Journal of Heat Transfer, 105, 485-492.

UDELL, K. S. (1985). < Heat transfer in porous media considering phase change and capillarity-the heat pipe effect $\searrow$.pdf>. International Journal of Heat and Mass Transfer, 28(2), 485-495.

Udell, K. S. (1998). <Application of in situ thermal remediation technologies for DNAPL removal.pdf>. Groundwater Quality: Remediation and Protection

Udell, K. S., \& Stewart, L. D. (1992). Combined steam injection and vacuum extraction for aquifer cleanup. In.

Yuan, Y., Ning, X.-a., Zhang, Y., Lai, X., Li, D., He, Z., \& Chen, X. (2020). Chlorobenzene levels, component distribution, and ambient severity in wastewater from five textile dyeing wastewater treatment plants. Ecotoxicology and Environmental Safety, 193, 110257. doi:https://doi.org/10.1016/j.ecoenv.2020.110257

Zuhair Al Yousef1, H. A., and Mohammed Al Otaibi3. (2014). <an overview of steam injection project in Fractured Carbonate Reservoirs in the Middle East.pdf>. Journal of Petroleum Science Research doi:10.14355/jpsr.2014.0303.01

\section{Figures}

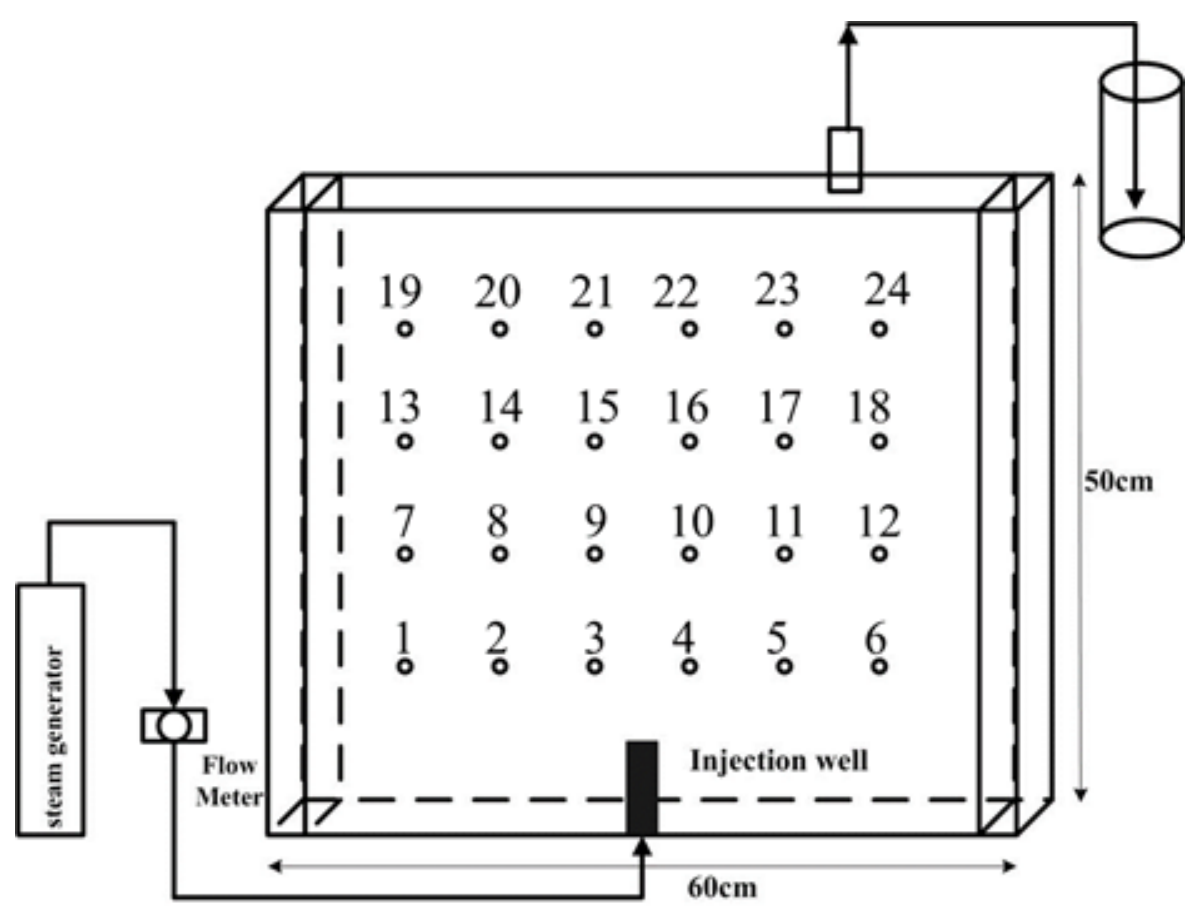

Figure 1

Schematic diagram of the experimental setup 

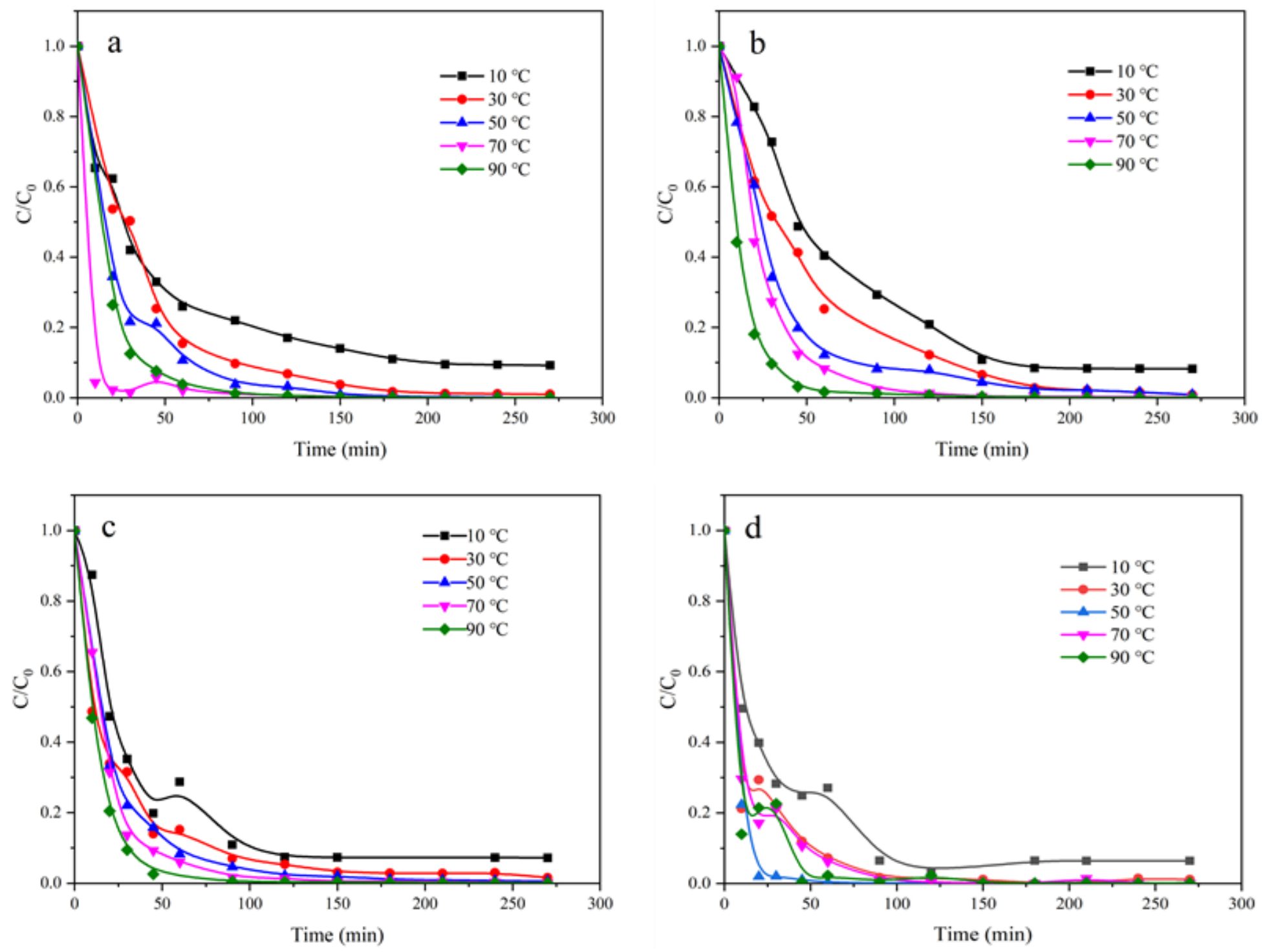

Figure 2

Changes in chlorobenzene concentration in the aqueous phase at different temperatures in (a) coarse, (b) medium, and (c) fine sand and (d) silt. 

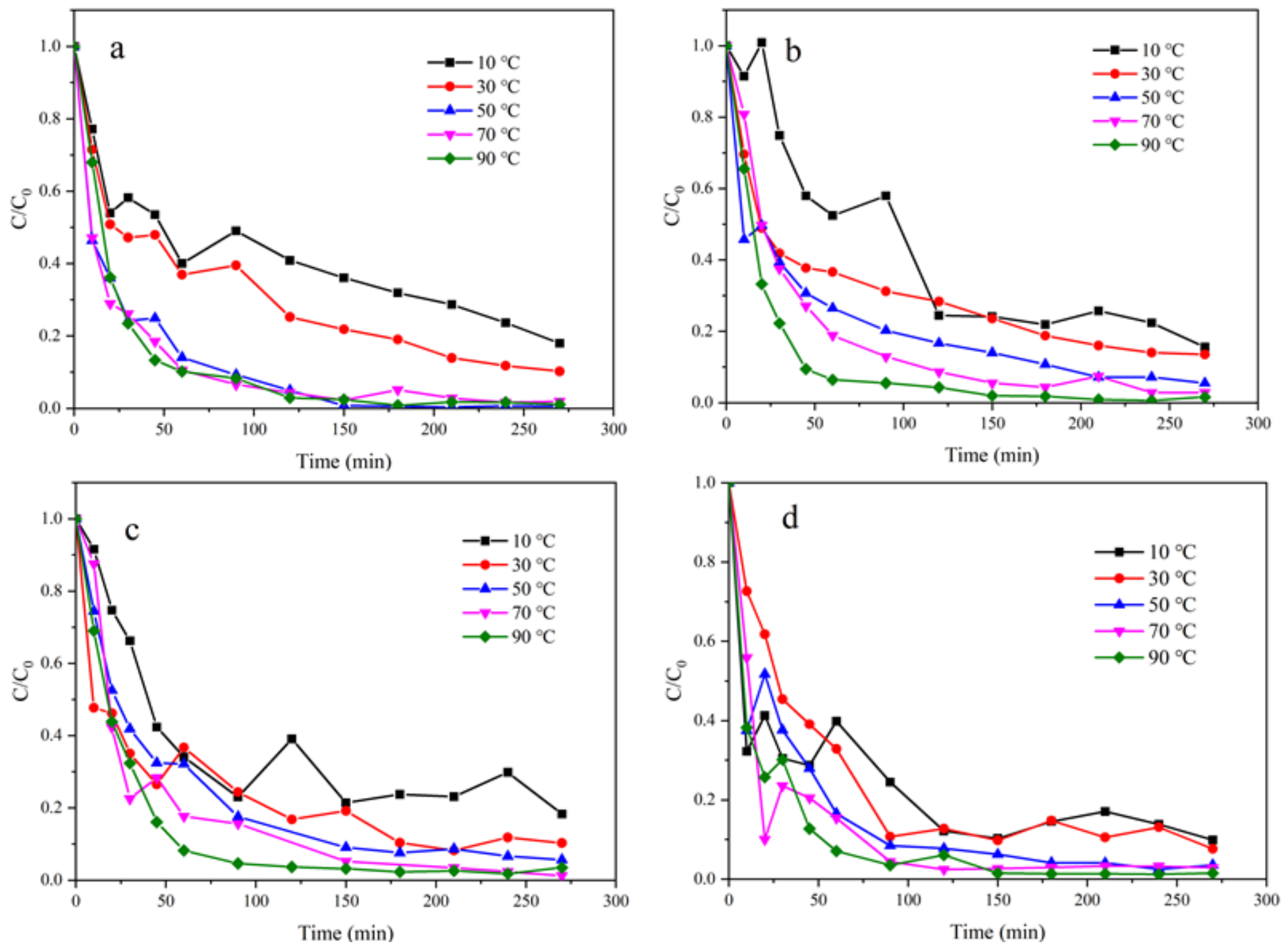

Figure 3

Changes in naphthalene concentration in the aqueous phase at different temperatures in (a) coarse, (b) medium, and (c) fine sand and (d) silt. 

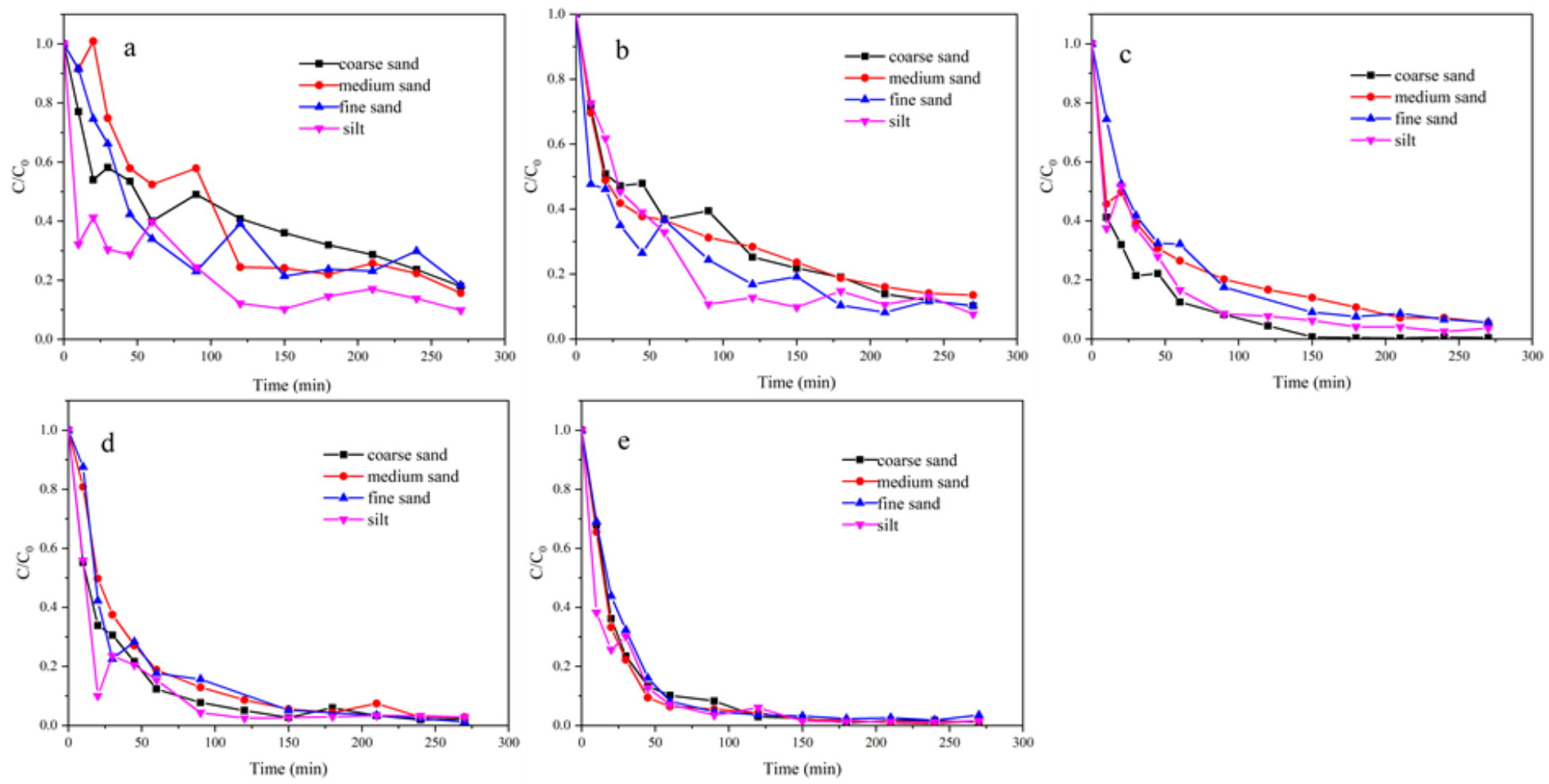

Figure 4

Changes in naphthalene concentration in different media at (a) 10, (b) 30, (c) 50, (d) 70, and (e) $90{ }^{\circ} \mathrm{C}$.
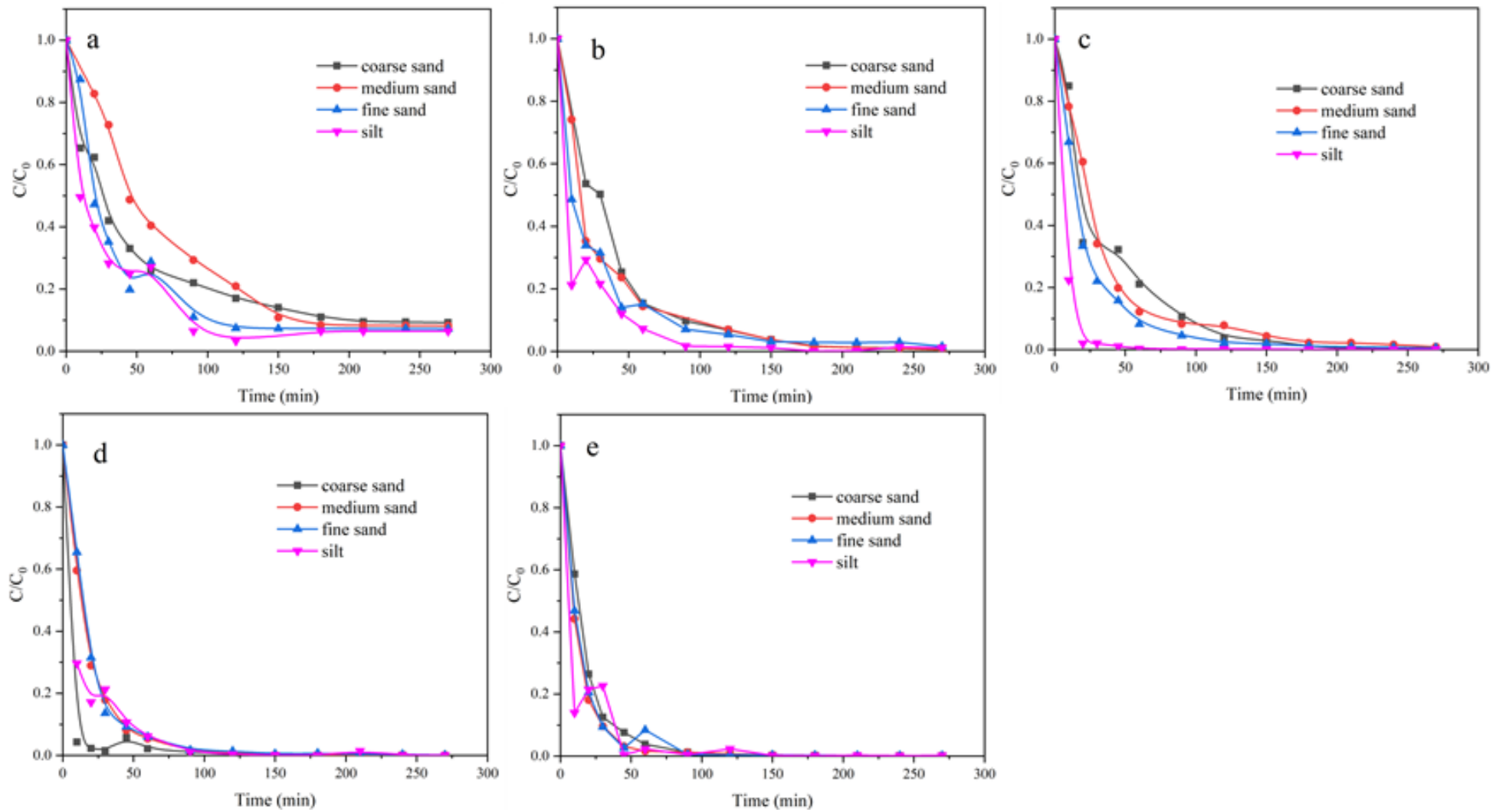

Figure 5

Changes in chlorobenzene concentration in different media at (a) 10, (b) 30, (c) 50, (d) 70, and (e) $90{ }^{\circ} \mathrm{C}$. 

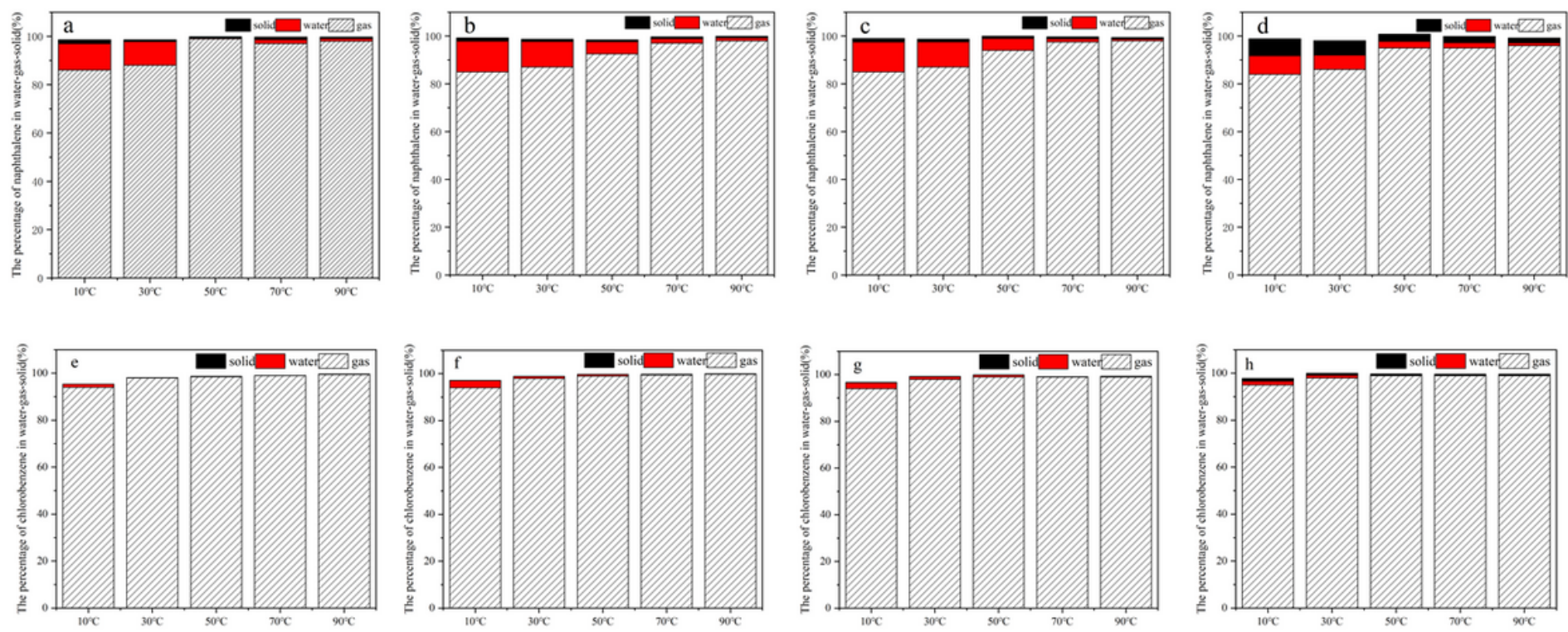

\section{Figure 6}

Percentage of naphthalene as a solid/liquid/gas in (a) coarse, (b) medium, and (c) fine sand and (d) silt and percentage of chlorobenzene as a solid/liquid/gas in (e) coarse, (f) medium, and (g) fine sand and (h) silt.
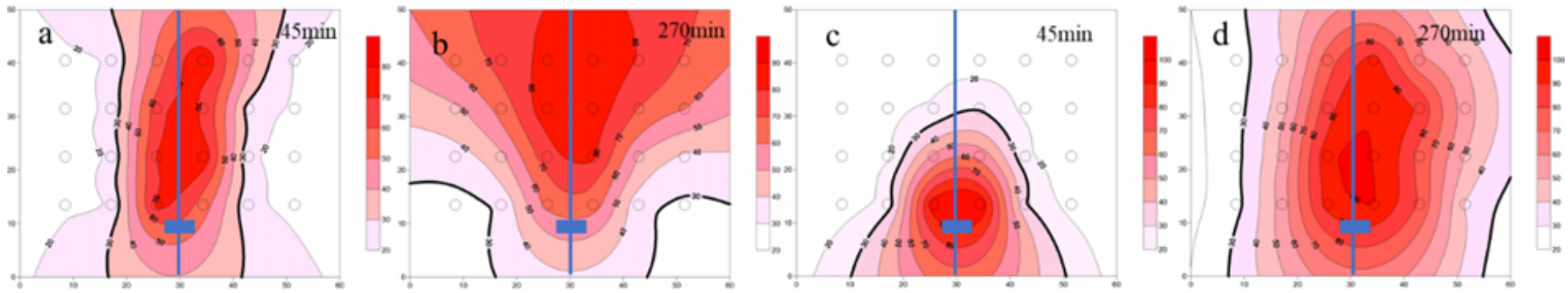

Figure 7

Distribution of the temperature field in coarse sand (a-b) and fine sand (c-d)

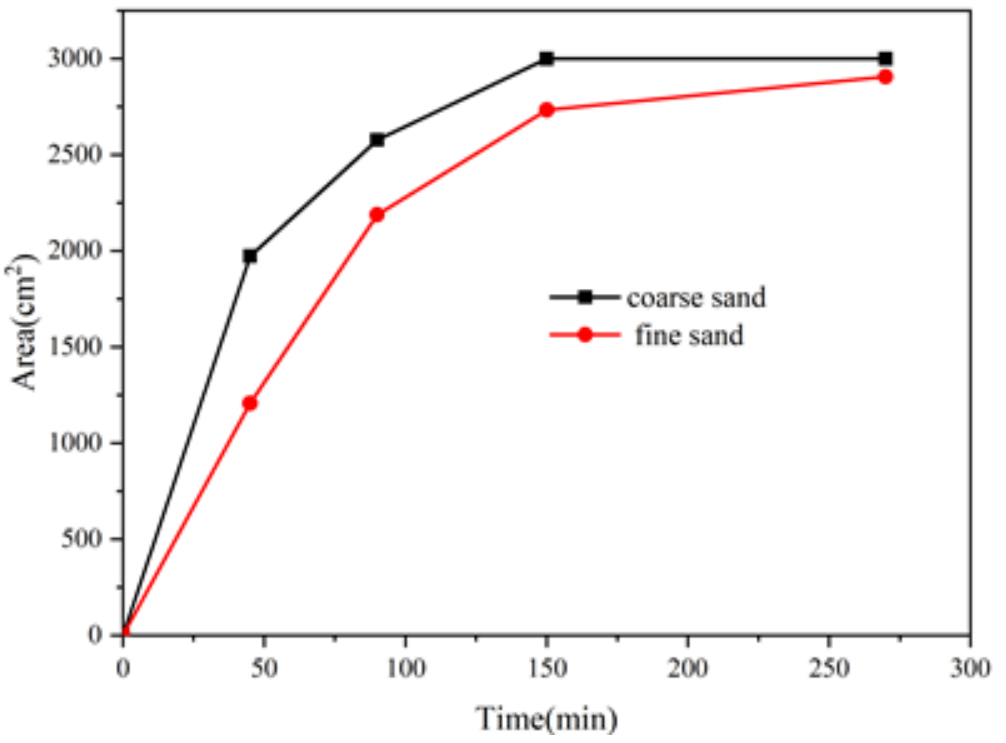

Figure 8 


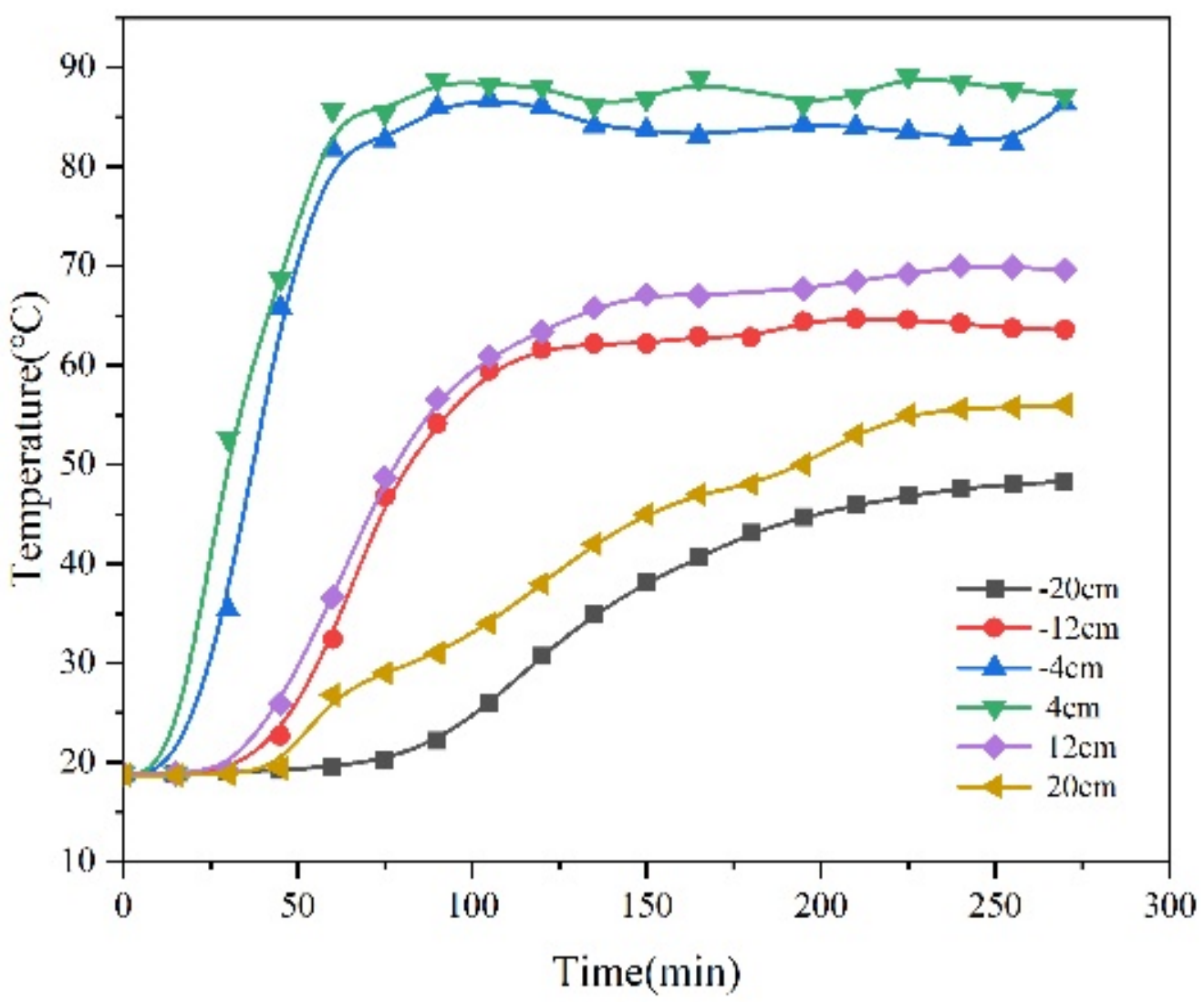

Figure 9

Temperature changes at different locations in coarse sand at $270 \mathrm{~min}$.

(a)

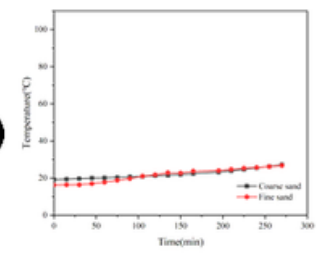

(b)

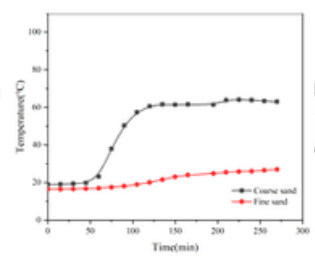

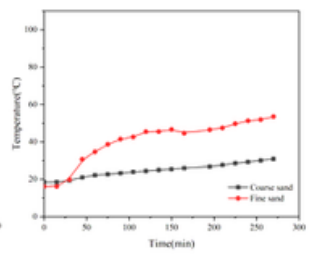

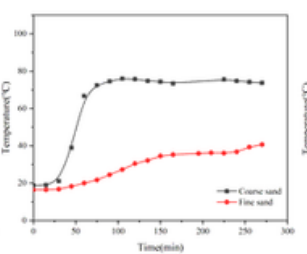

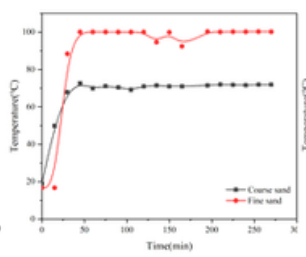
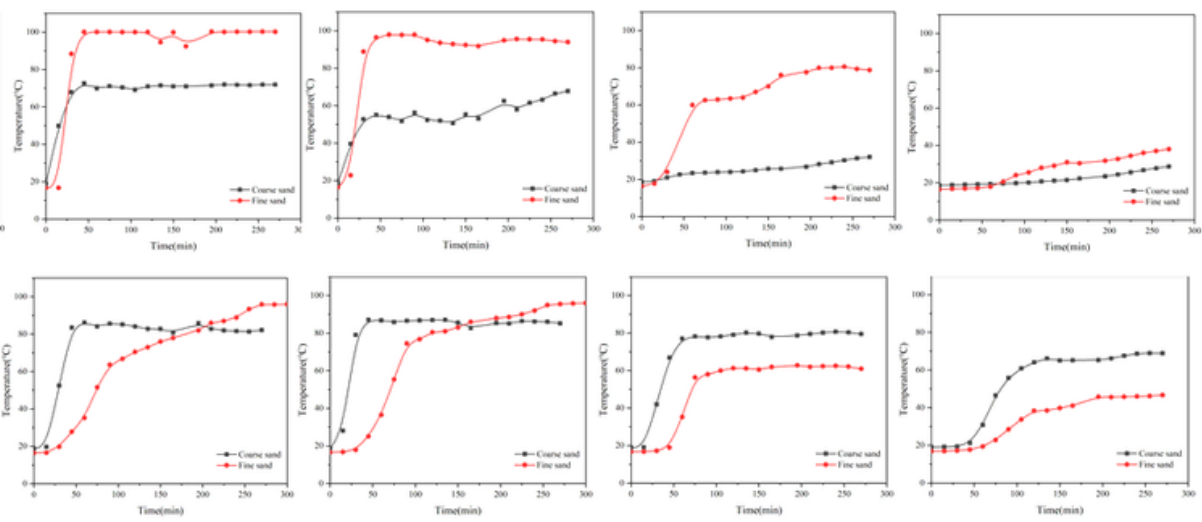

\section{Figure 10}

Temperature changes at the same location in coarse sand and fine sand at $270 \mathrm{~min}$. (a) First row and (b) fourth row above the steam injection point. 

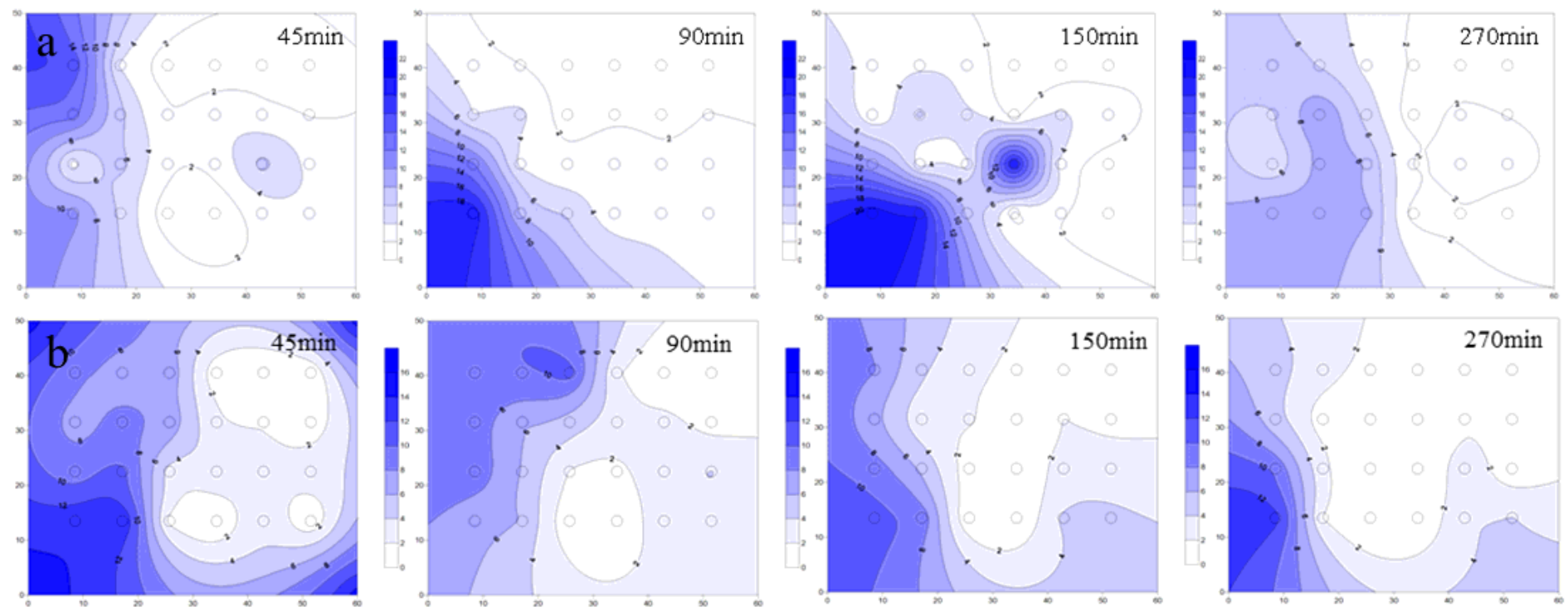

Figure 11

Isoline of chlorobenzene concentration in (a) coarse and (b) fine sand.

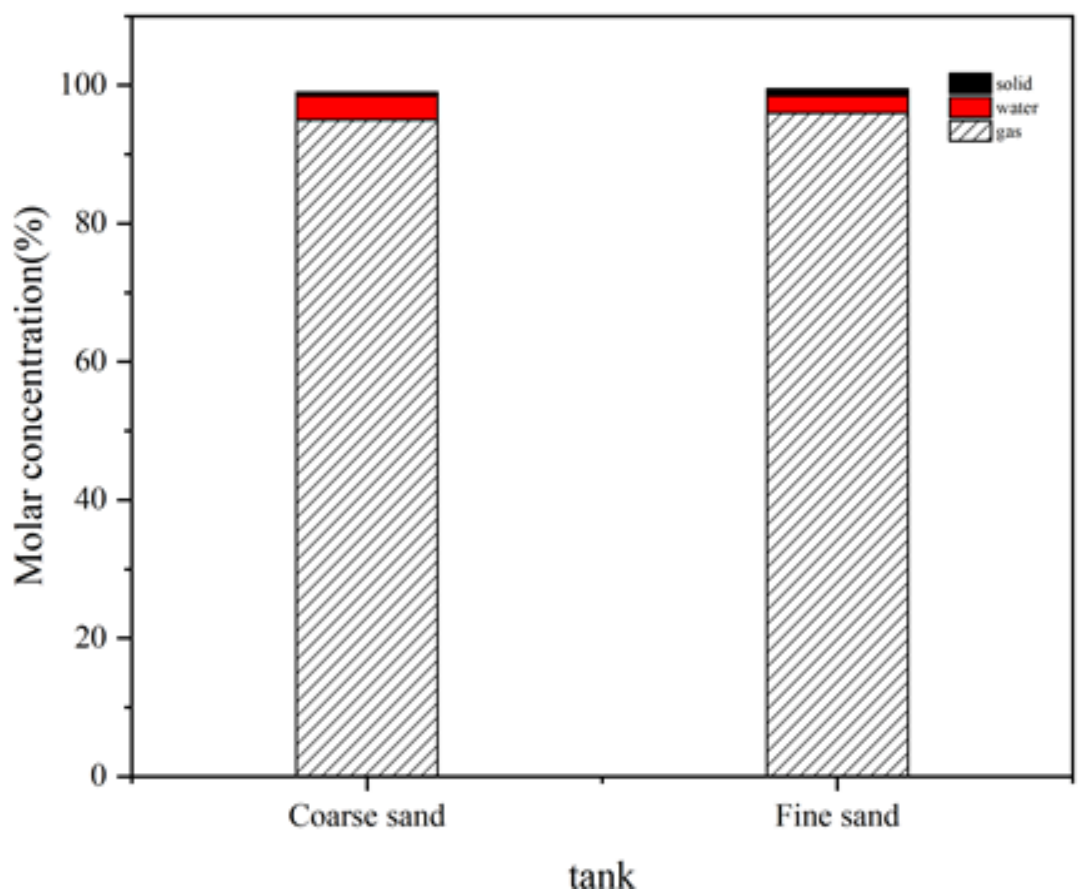

Figure 12

Proportion of chlorobenzene in different phases

\section{Supplementary Files}

This is a list of supplementary files associated with this preprint. Click to download.

- Supplementarymaterial.docx 